\title{
Allocupreide Sodium
}

National Cancer Institute

\section{Source}

National Cancer Institute. Allocupreide Sodium. NCI Thesaurus. Code C80266.

A copper(I) complex used as an antiinflammatory drug and antiarthritic agent. 